\begin{tabular}{|l|c|c|c|c|}
\hline Cuadernos I. Geográfica & 22-23 & pp. 33-56 & Logroño & 1996-97 \\
\hline
\end{tabular}

\title{
PROCESOS GEOMÓRFICOS HISTÓRICOS Y SU RELACIÓN CON LA ACTIVIDAD HUMANA EN EL PIRINEO CENTRAL ESPAÑOL
}

\author{
JOSÉ M. GARCÍA RUTZ \\ BLAS L. VALERO GARCÉS'
}

\begin{abstract}
RESUMEN. El Pirineo Central español muestra una gran diversidad de procesos geomórficos en relación con la beterogeneidad topográfica $y$ climática y en función del fuerte gradiente altitudinal. La actividad bumana en los últimos milenios ba contribuido mucho a alterar el paisaje original y su dinámica bidromorfológica: el piso superior del bosque fue eliminado mediante incendios durante la Edad Media, con el fin de ampliar la superficie de pastos de verano; $y$ las laderas solanas por debajo de $1600 \mathrm{~m}$ se han cultivado en condiciones topográficas muy difíciles, siendo quemadas frecuentemente para mejorar las condiciones del pastoreo. En la actualidad son bien visibles las buellas de esta actividad bumana: en el piso subalpino movimientos en masa superficiales $y$ densas redes de rills han provocado la pérdida de gran parte del suelo y la expansión de terracillas de gelifluxión; en montaña media el arroyamiento superficial ba aumentado mucho la pedregosidad superficial y se han formado coladas de piedras de diferente envergadura en laderas y en cauces fluviales. Los ríos muestran una elevada torrencialidad, con predominio de cauces inestables y de la carga gruesa. Los autores aportan información sobre algunos fenómenos geomorfológicos bistóricos relacionados con la actividad bumana.
\end{abstract}

ABSTRACT. The Central Spanish Pyrenees show a great diversity of geomorpbic processes in relation with topographic and climatic heterogeneity and according to the strong altitudinal gradient. Human activity in the last millenniums bas contributed to disturb the original landscape and its hydromorpbological dynamics: the upper forest belt was eliminated by means of fire during the Middle Age, in order to enlarge the extent of summer pastures; and the billslopes located under $1600 m$ were cultivated in beavy topograpbic conditions, being frequently burnt in order to improve the quality of pastures. At present, evidences of this buman activity are visible everywbere; in the subalpi-

1. Depto. Erosión y Usos del Suelo. Instituto Pirenaico de Ecología, CSIC, Zaragoza, España. 
JOSÉ M. ${ }^{a}$ GARCÍA RUIZ - BLAS L. VALERO GARCÉS

ne belt mass movements and dense rill networks caused the loss of many soils and the expansion of gelifluxion terracettes; in middle mountain, overland flow bas much increased the soil surface stoniness, and debris flows of different size have developed on the billslopes and on the river channels. Rivers show a strong torrentiality, prevailing unstable channels and coarse sediment transport. The autbors apport information on some bistorical geomorphic processes, related with buman activity.

Palabras clave: Procesos de erosión, actividad antrópica, evolución del paisaje, Pirineos.

Key words: Erosion processes, human activity, landscape evolution, Pyrenees.

\section{Introducción}

Es bien conocida la actual organización espacial de los procesos geomórficos en el Pirineo Central español (GARCÍA RUIZ \& PUIGDEFÁBREGAS, 1982; GARCÍA RUIZ et al., 1990; GONZÁLEZ et al., 1995) y su relación con la distribución de los pisos bioclimáticos y con los diferentes usos del suelo. En la actualidad se ha podido constatar una reducción espacial de las áreas más activas geomorfológicamente, especialmente en montaña media, donde el descenso de la presión demográfica y el abandono de tierras de cultivo favorecen la colonización vegetal (MOLINILLO et al., 1997; GARCÍA RUIZ et al., 1995). Las fuentes de sedimentos tienden a limitarse a los taludes próximos a los cauces (GARCÍA RUIZ et al., 1997), a las cabeceras activas de torrentes, a los badlands en afloramientos margosos y a laderas afectadas por densas redes de rills. Localmente, sin embargo, han aparecido nuevas fuentes de sedimentos vinculadas al turismo (en estaciones de esquí) (PUIGDEFÁBREGAS \& ALVERA, 1986) y al desarrollo de las vías de comunicación. Son frecuentes los movimientos en masa de pequeña envergadura (debris flows ligados a fracturas o localizados en la parte alta de las laderas; deslizamientos planares por encima del límite superior del bosque) pero están escasamente conectados con la red fluvial y aportan pocos sedimentos.

Es evidente que en áreas intensamente ocupadas por el hombre las perturbaciones sufridas por la vegetación y los grandes cambios de uso del suelo condicionan la intensidad de los procesos geomórficos, más incluso que las pequeñas fluctuaciones climáticas (LEOPOLD, 1978). Desde hace al menos 6.000 años existen evidencias de poblaciones estables en el Pirineo -cada vez más numerosas y con mayor capacidad tecnológica- que han eliminado el bosque de muchos lugares, han quemado, pastoreado y cultivado en laderas pendientes. Las consecuencias de esta actividad son todavía visibles en el paisaje actual: extensas laderas han perdido gran parte del suelo y se conservan las huellas de movimientos en masa relacionados con ciertos modelos de gestión. 
Además, algunos ríos han funcionado de manera muy torrencial hasta hace pocas décadas, con cauces muy inestables y predominio de la carga gruesa, prueba de la intensa actividad geomórfica del conjunto de la cuenca.

En este trabajo se presentan los datos disponibles sobre procesos geomórficos en época histórica en el Pirineo Central, la mayor parte elaborados por el Departamento de Erosión y Usos del Suelo del Instituto Pirenaico de Ecología. El objetivo que se persigue consiste en relacionar tales procesos con algunos rasgos fundamentales de la actividad humana histórica y explicar las estrechas interacciones existentes entre dinámica geomorfológica y cambios de uso del suelo a diferentes escalas espaciales y temporales.

\section{El área de estudio}

El Pirineo Central español se organiza en una sucesión de bandas paralelas alargadas de oeste a este, que la red fluvial atraviesa formando valles orientados de norte a sur (Fig.1). 1) La banda más septentrional está formada por materia-

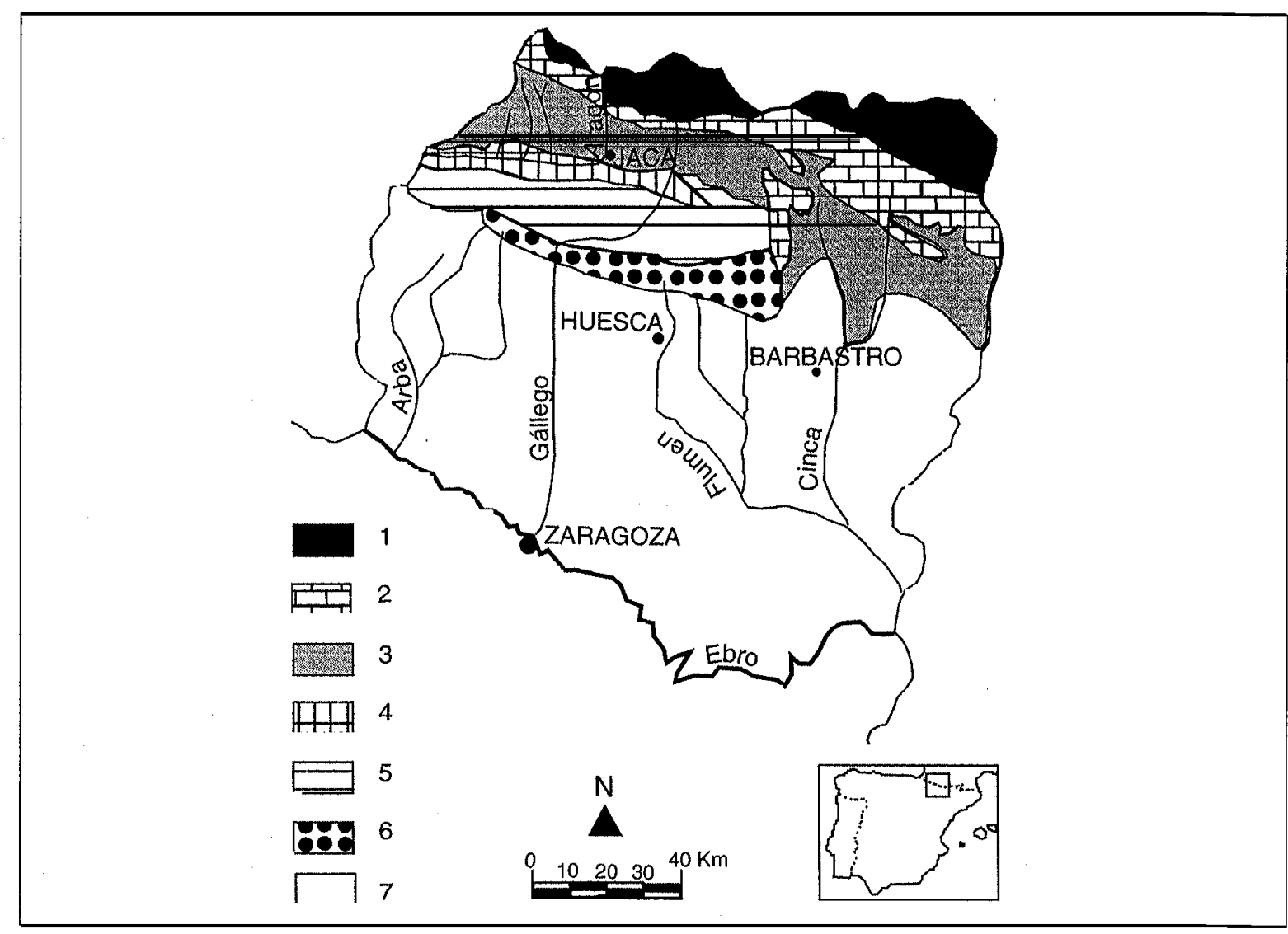

Figura 1. Grandes unidades estructurales del Pirineo Central español. 1: Pirineo Axial (Paleozoico). 2: Sierras Interiores (Cretácico y Eoceno). 3: Flysch eoceno. 4: Margas eocenas. 5: Molasas prepirenaicas (Oligoceno). 6: Sierras Exteriores (Cretácico y Eoceno). 7: Depresión del Ebro (Oligoceno y Mioceno). 
les paleozoicos intensamente plegados (calizas, areniscas, conglomerados, esquistos y pizarras) y afectados por la acción glaciar cuaternaria. 2) Inmediatamente al sur se localizan las Sierras Interiores, un gran anticlinal cabalgante, compuesto por calizas cretácicas y eocenas, con areniscas y calizas margosas intercaladas. El relieve está dominado por escarpes verticales, karstificación intensa, numerosos circos glaciares, grandes derrubios y canales de avalancha activos. 3) El flysch eoceno está muy plegado pero su homogeneidad litológica produce un relieve más uniforme, con divisorias suaves que descienden progresivamente hacia el sur. Los grandes glaciares dejaron abundantes depósitos morrénicos laterales y glaciolacustres. 4) La Depresión Interior se desarrolla en margas del Eoceno y forma un amplio valle dominado por depósitos cuaternarios (terrazas y glacis). 5) El Prepirineo está formado por una sucesión de cuestas de areniscas y arcillas oligocenas de origen fluvial y deltaico (molasas) y, más al sur, por las Sierras Exteriores, un anticlinal cabalgante que separa a los Pirineos de la Depresión del Ebro.

Temperaturas y precipitaciones muestran un doble gradiente. De oeste a este disminuye la influencia atlántica y aumenta la mediterránea. De igual forma, la precipitación se reduce de norte a sur, a medida que aumenta la temperatura. En las áreas más elevadas se ha estimado una precipitación media anual de más de $2.500 \mathrm{~mm}$ (RIJCKBORST, 1967). La isoterma de $0^{\circ}$ durante la estación fría se localiza entre 1.600 y 1.700 m (GARCÍA-RUIZ et al., 1986) y por encima de ese umbral la acumulación de nieve es muy importante.

El área agrícola llega hasta 1500-1600 m, ocupando los fondos de valle y rellanos colgados. En el pasado las laderas solanas fueron cultivadas de forma general (LASANTA, 1989), pero ahora han sido totalmente abandonadas (LASANTA, 1988). Entre 1.500 y $1.750-1.800 \mathrm{~m}$ se conservan extensos bosques de pinos, acompañados de Abies alba y Fagus sylvatica. Entre 1750 y $2400 \mathrm{~m}$ se desarrolla el piso de pastos subalpinos y alpinos, utilizados en verano por el ganado.

\section{Métodos}

Durante los últimos 15 años el Departamento de Erosión y Usos del Suelo del Instituto Pirenaico de Ecología ha centrado sus objetivos en el estudio de la organización espacial de los procesos geomórficos en relación con las actividades humanas y su variabilidad temporal. Para ello se ha servido de diversos métodos, entre los que destacan:

- Elaboración de mapas geomorfológicos a escala 1: 50.000, utilizando fotografias aéreas desde 1929 (disponibles en muy pocos lugares) hasta 1990, y métodos SIG para discriminar la distribución de los procesos geomórficos (GONZÁLEZ et al., 1995).

- Análisis de la estabilidad de suelos afectados por movimientos en masa (PUIGDEFÁBREGAS \& GARCÍA-RUIZ, 1983). 
PROCESOS GEOMÓRFICOS HISTÓRICOS Y SU RELACIÓN CON LA ACTIVIDAD HUMANA

- Datación de restos orgánicos (árboles y cenizas) tomados en derrubios de ladera y en grandes coladas de piedras. Ocasionalmente se han utilizado referencias históricas de archivos (MARTí et al., 1997).

- En la Estación Experimental "Valle de Aísa" se han reproducido distintos usos del suelo en parcelas cerradas de $10 \times 3 \mathrm{~m}$, con almacenamiento continuo de la escorrentía y control de los sedimentos durante cada evento pluviométrico (GARCÍA-RUIZ et al., 1995). Algunos usos del suelo estuvieron vigentes siglos atrás y aportan información sobre el funcionamiento de laderas durante el llamado sistema tradicional de gestión. La cuenca experimental "Loma de Arnás", con estación meteorológica y sistemas para medición continua del caudal y del transporte de sedimentos, aporta información sobre fuentes y balances de sedimentos en áreas intensamente perturbadas por la actividad humana (GONZÁLEZ et al., 1997).

- El estudio de los sedimentos de llanuras aluviales y conos de deyección ha permitido observar posibles cambios en la dinámica fluvial y relacionar las áreas más alteradas por el hombre con ciertos rasgos de los sedimentos (MARTíNEZCASTROVIEJO \& GARCÍA-RUIZ, 1990; GÓMEZ-VILLAR, 1996).

- El estudio de sedimentos acumulados en lagos de alta montaña ha permitido identificar y datar los grandes momentos de la deforestación del piso superior del bosque, así como sus consecuencias geomorfológicas (MONTSERRAT, 1992; VALERO \& MARTÍ-BONO, 1997).

\section{Resultados}

Los resultados obtenidos permiten distinguir tres conjuntos de problemas que han podido coexistir en el tiempo y en el espacio: Erosión ligada a grandes incendios, grandes coladas de piedras y erosión ligada a la agricultura de laderas. En la Fig. 2 se indican las áreas de trabajo citadas en el texto.

Figura 2.

Localización de las áreas de trabajo citadas en el texto.

1: Lago de Tramacastilla.

2: Estación Experimental

"Valle de Aísa". 3: San

Adrián de Sasave. 4: Cuenca

Experimental "Loma de Arnás”. 5: Barranco de Arás.

6: Biescas. 7: Espuéndolas.

8: Río Ijuez. 9: Río Aurín. 10: Bentué de Rasal.

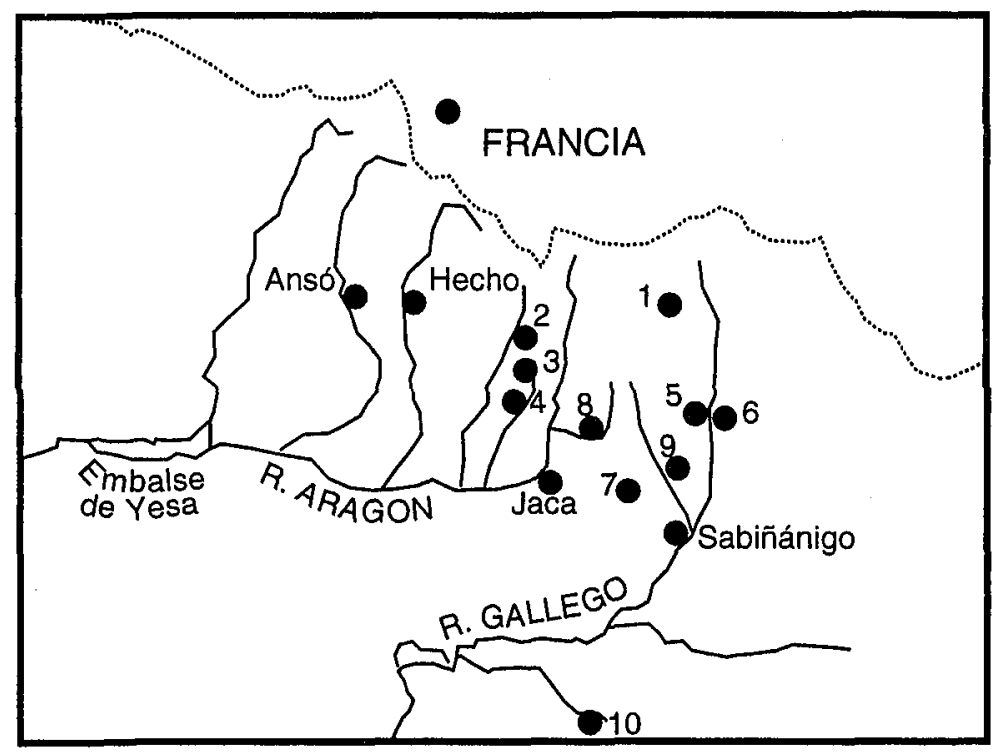


JOSÉ M. ${ }^{a}$ GARCÍA RUIZ - BLAS L. VALERO GARCÉS

\subsection{La erosión ligada a los grandes incendios}

El análisis polínico de sedimentos acumulados en lagos de alta montaña ha proporcionado información muy valiosa sobre la evolución de la vegetación y de las actividades humanas en los últimos miles de años, pudiendo identificarse dos momentos con erosión más intensa.

El lago de Tramacastilla (alto valle del Gállego) se localiza en una cubeta de origen glaciar a $1680 \mathrm{~m}$ s.n.m. de la que el hielo se retiró muy pronto (aprox. 30.000 años BP). MONTSERRAT (1992) extrajo un testigo de sondeo de $11 \mathrm{~m}$ de potencia que abarca desde el Pleniglaciar hasta la actualidad. El nivel inferior del sondeo ( $4.3 \mathrm{~m}$ de arcillas azules masivas y laminadas) corresponde a la sedimentación ocurrida desde la retirada de los hielos y durante el Tardiglaciar con un paisaje estepario en el que poco a poco se instalan enebros, abedules y pinos. Por encima aparecen $2.7 \mathrm{~m}$ de sedimentos esencialmente orgánicos, masivos o laminados que según MONTSERRAT (1992) coinciden con el inicio del Holoceno (10.000 BP), en el que el espectro polínico muestra el predominio del abedul con presencia de Quercus, Corylus y Ulmus, desplazamiento progresivo del pino y aparición de otras especies del bosque mixto (Fraxinus, Tilia, Alnus, Taxus) hacia el 6.000 B.P.

El primer nivel detrítico significativo corresponde a un cambio importante de los espectros polínicos hacia $3.980 \pm 50 \mathrm{BP}$, apareciendo taxones propios de espacios abiertos. El aumento del aporte detrítico al lago está representado por la disminución del contenido en materia orgánica de los sedimentos y el aumento del porcentaje de partículas de tamaño arena. Este cambio sedimentario y geobotánico es sólo temporal, pues pronto volvió a predominar la sedimentación orgánica coincidiendo con la expansión de Pinus y Fagus. Aunque todas las hipótesis siguen abiertas, no es descabellada la idea de un primer episodio deforestador consciente, de mediana entidad y corta duración, con el fin de ampliar la extensión de los pastos de verano.

Es interesante tener en cuenta que en una época muy temprana también se han detectado incendios en el valle de Bentué, en la parte más meridional de los Pirineos Centrales. Al pie de un escarpe de caliza (Monte Peiró) un derrubio erosionado por divagación lateral del río Garona muestra su estructura sedimentaria interna, con un claro nivel de cenizas y ramas quemadas que separa dos niveles bien diferentes. Bajo las cenizas el derrubio aparece dominado por clastos pequeños (menos de $5 \mathrm{~cm}$ de media). Sobre las cenizas predominan los grandes bloques, incluso de más de $60 \mathrm{~cm}$ de eje (b). La edad de las cenizas es $3340 \pm 70$ BP (radiocarbono calibrado, UBAR-447).

No debe olvidarse que en la alta montaña pirenaica hubo asentamientos ocasionales alrededor del 4.000 BP, como lo prueba la frecuente presencia de dólmenes y túmulos eneolíticos (MAISAN \& UTRILLA, 1996; ANDRÉS, 1992). Algunos 
TRAMACASTILLA LAKE

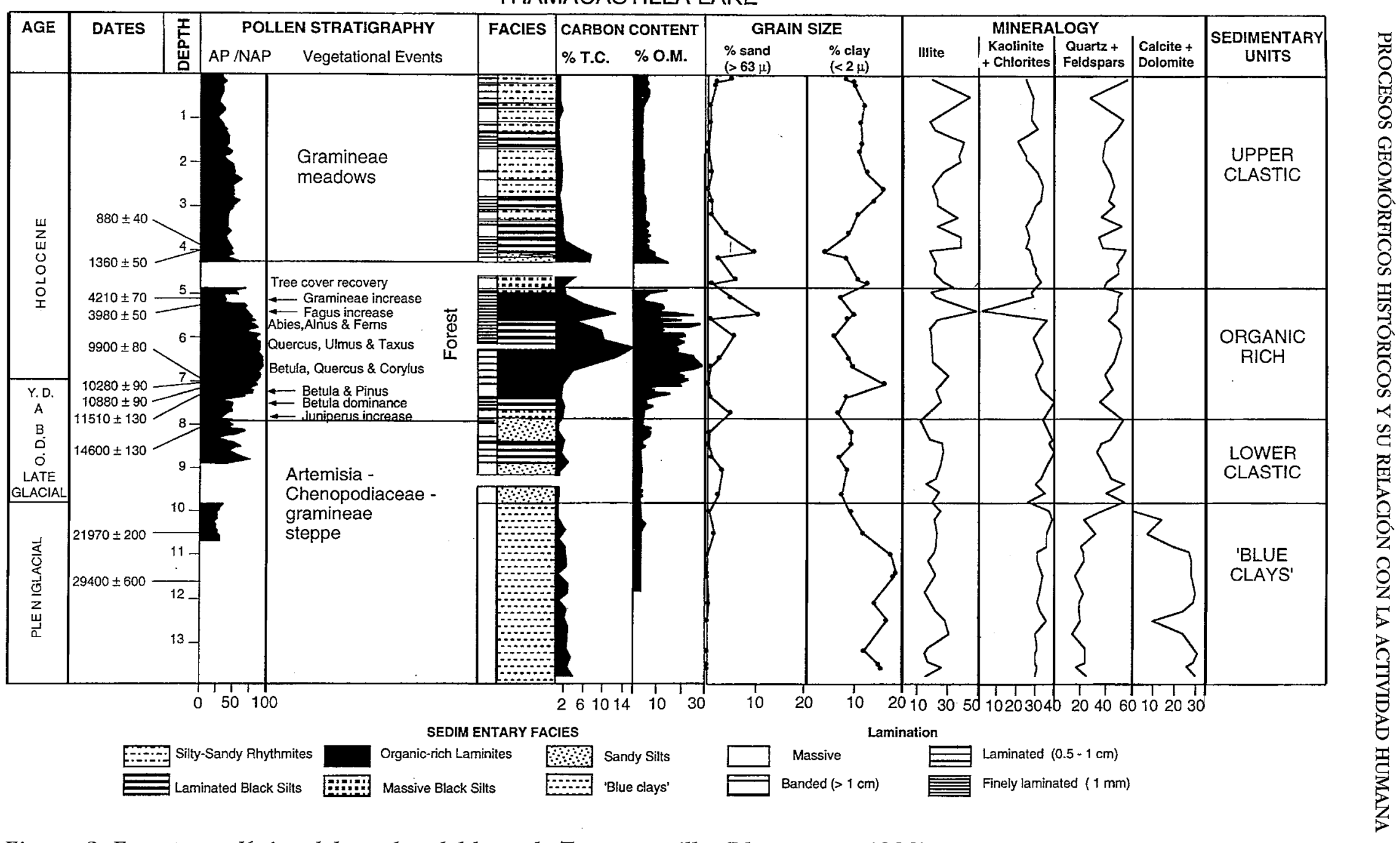


asentamientos agrícolas se habían localizado ya en el Prepirineo (valle del Esera) alrededor del 6.400 B.P. (BALDELLOU \& UTRILLA, 1994; RODANÉS \& RAMÓN, en prensa).

El segundo momento de erosión fue mucho más importante. Los últimos $4.6 \mathrm{~m}$ del sondeo corresponden a sedimentos detríticos, inicialmente masivos $(0.4 \mathrm{~m})$ y con mayores porcentajes de arena y cuarzo, y más tarde laminados. Este cambio está acompañado en el espectro polínico (Fig.3) por el predominio de plantas heliófilas que indican la desaparición de la cobertera arbórea. La masiva sedimentación de ritmitas, con una tasa diez veces superior a la de los depósitos lacustres anteriores, permitió a MONTSERRAT (1992) establecer que los procesos de deforestación fueron masivos a partir del año 1000 de nuestra era, con la consiguiente degradación de los suelos y erosión. La pérdida de la cubierta arbórea sería prácticamente total a partir del siglo XII, con la expansión de la trashumancia hacia las estepas de la Depresión del Ebro (UBIETO, 1981) tras la conquista de los reinos musulmanes. Posteriormente la presión ganadera fue lo suficientemente fuerte como para impedir la reinstauración natural del bosque, de manera que en gran parte del Pirineo los pastos supraforestales se inician a 1600-1700 m (e incluso más abajo en amplios valles glaciares, como en la cabecera del Aragón Subordán o en Ansó), cuando de forma natural deberían hacerlo a partir de entre 2000 y $2200 \mathrm{~m}$ s.n.m.

La sustitución del bosque por pastos implicó un descenso altitudinal del área de procesos periglaciares o, como señala HÖLLERMANN (1985), del límite inferior de la solifluxión. La consecuencia fue el desplazamiento masivo de los suelos localizados en laderas de más de $25-30^{\circ}$ de pendiente por medio de deslizamientos planares (GARCÍA RUIZ et al., 1990) y la formación de terracillas de Festuca skia y $F$. Gautieri). Fenómenos similares han podido constatarse en otras montañas europeas durante los últimos siglos. Así, BALLANTYNE (1994) reconoce una intensificación de la solifluxión desde el siglo XVI en Escocia debida al pastoreo y la reducción de la cubierta vegetal. GAMPER (1994) concluye que en los Alpes suizos se identifican dos máximos de solifluxión en torno a 4000 BP y 2000-750 BP vinculados a una continentalización del clima, aunque sin descartar la acción antrópica.

En las laderas más pendientes se instalaron densas redes de rills y cabeceras activas de torrentes, quedando los suelos profundos, de origen forestal, relegados a las zonas menos pendientes, donde pueden haberse acumulado varios metros de regolito (GARCÍA RUIZ \& PUIGDEFÁBREGAS, 1982).

González et al. (1995) comprobaron mediante la aplicación de técnicas SIG que en el antiguo piso superior del bosque, hoy ya deforestado, los movimientos en masa poco profundos y los procesos de arroyamiento superficial están comparativamente mucho más extendidos que en las laderas forestadas o que en el piso alpino en condiciones de pendiente muy similares. De hecho, 
Puigdefábregas \& Alvera (1986) confirmaron que la sustitución de densos pinares por pastos de verano ha dado lugar a un aumento en la escorrentía y transporte de sedimentos. Se realizó una comparación entre dos cuencas, una cubierta de pastos (antiguamente ocupada por el bosque) y la otra con un denso bosque de Pinus sylvestris y Pinus uncinata. La escorrentía media del pasto $\left(12.9 \mathrm{l} / \mathrm{s} / \mathrm{Km}^{2}\right)$ es doble que la del bosque $\left(6.2 \mathrm{l} / \mathrm{s} / \mathrm{Km}^{2}\right)$ y los sedimentos en suspensión son diez veces superiores en la cuenca de pasto. Estos resultados muestran hasta qué punto se ha alterado el comportamiento hidromorfológico de laderas inicialmente forestales.

\subsection{Las grandes coladas de piedras}

Aunque toda la montaña media aparece salpicada por pequeñas coladas de piedras (cicatrices de unos pocos metros cuadrados; lenguas de 25 a $50 \mathrm{~m}$ de longitud) en laderas muy alteradas históricamente por el hombre, excepcionalmente pueden alcanzar grandes dimensiones. La formación de pequeñas coladas de piedras (billslope debris flows, según la terminología de BRUNSDEN, 1979) es un hecho muy habitual en el Pirineo con ocasión de precipitaciones de elevada intensidad, sobre todo en exposiciones solanas, entre 900 y 1500 m s.n.m. y en laderas de bosque claro, matorrales y áreas afectadas por repoblaciones forestales (GARCÍA-RUIZ \& PUIGDEFÁBREGAS, 1982).

Muchos trabajos han demostrado el papel de las coladas de piedras como agentes muy activos de la evolución del relieve y del transporte de sedimentos en áreas de montaña (CAINE, 1980; JOHNSON \& RODINE, 1984). En la zona de flysch del Pirineo Central se han producido algunas grandes coladas del tipo de las descritas por DE JONG (1992), ocurridas durante eventos extraordinarios de precipitación, dando lugar a lenguas bien definidas de gran tamaño, ocupando incluso el fondo de valles amplios. En el Pirineo Central se han identificado dos de estas coladas de piedras, en el valle de Borau (San Adrián de Sasave) y en la Val Ancha (Espuéndolas), aunque no se excluyen otras similares, especialmente en la formación de los conos de deyección del valle del Gállego.

El Monasterio de San Adrián de Sasave se construyó a finales del siglo IX (SESMA, 1980) en la confluencia de los barrancos Calcín y Lopán, en la cabecera del valle de Borau, en una amplia zona llana. La iglesia actual es de estilo románico lombardo, de la segunda mitad del siglo XI. A mediados del siglo XX, sin embargo, solo permanecian visibles el tejado y la parte alta de los muros de la iglesia. Una gran colada de piedras había enterrado varios siglos antes la mayor parte de la iglesia y todas las dependencias del Monasterio. En las últimas décadas la iglesia ha sido exhumada después de haberse realizado una excavación que permite analizar las características de la colada de piedras. Algunas estructuras añadidas a la iglesia original ayudan a interpretar la evolución del movimiento en masa. 
Existe documentación que prueba la ocurrencia de un primer acarreo de sedimentos en el siglo XII, que parcialmente enterró al Monasterio. Esto está básicamente de acuerdo con la información procedente de varias fuentes. En primer lugar, los restos de un tronco que permanecía de pie en su sitio de enraizamiento se encontraron durante la excavación. La edad de este tronco, por medio de datación con radiocarbono calibrado, es $950 \pm 60$ años (UBAR 446), es decir, que fue un plantón entre 1030 y $1160 \mathrm{AD}$, a los que deberían añadirse otros 75-80 años que es la edad del árbol en el momento de morir, de acuerdo con el número de anillos contabilizados en el tronco. La muerte del árbol parece, pues, coincidir muy aproximadamente con el momento de la primera avalancha de sedimentos.

En segundo lugar, el acceso a la entrada principal de la iglesia se produce por medio de cinco escaleras descendentes. Esto es muy inusual, pues en todas las iglesias las escaleras de entrada van hacia arriba y no hacia abajo. La interpretación es que después de un enterramiento parcial de la iglesia la única posibilidad de acceso fué construir escaleras desde el nivel superior del depósito hasta la entrada. Otras escaleras descendentes fueron construidas en el muro meridional de la iglesia.

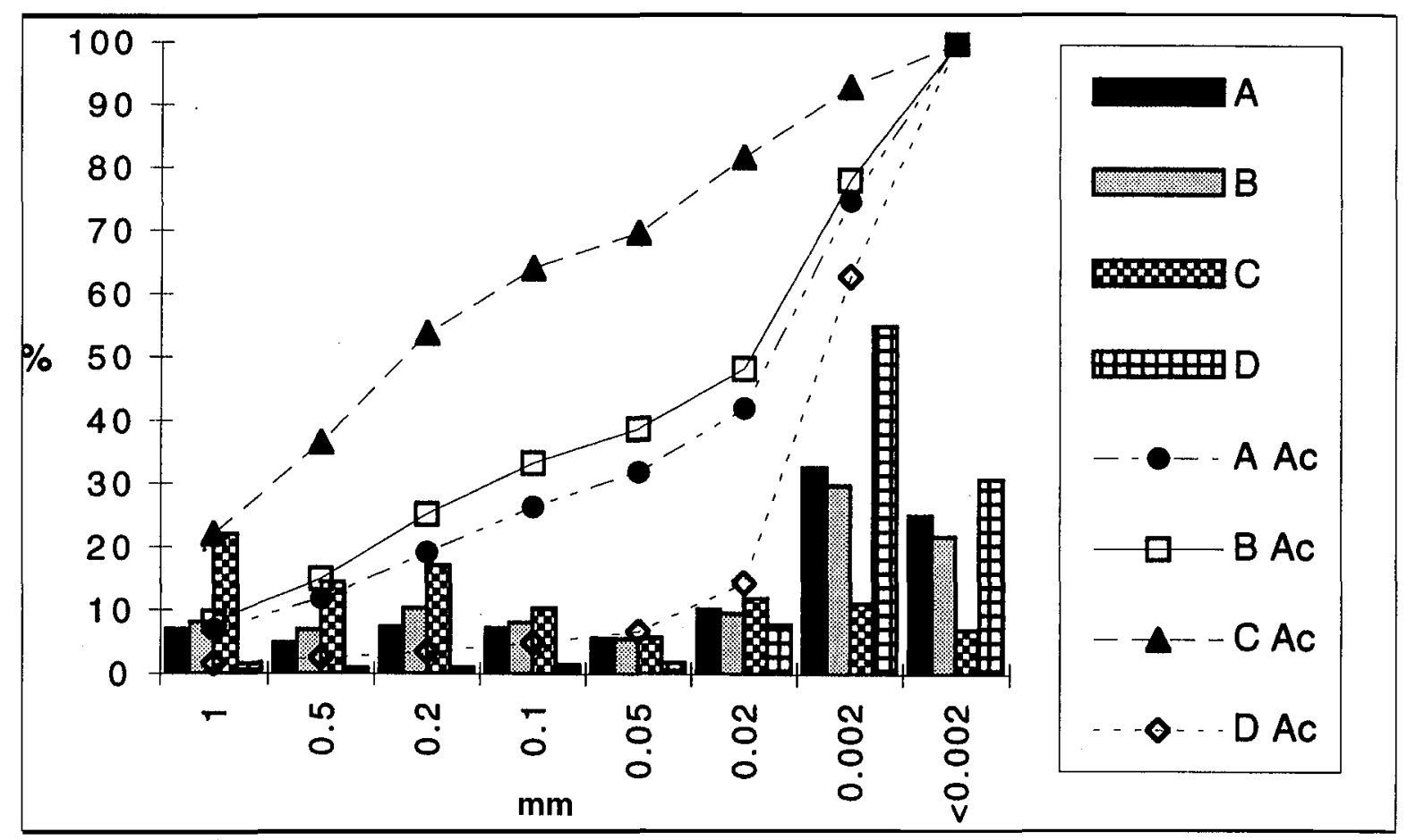

Figura 4. Granulometría de sedimentos en San Adrián de Sasave (partículas menores de $2 \mathrm{~mm}$ ). A: Colada de piedras del Monasterio de San Adrián de Sasave (cara sur). B: Colada de piedras del Monasterio de San Adrián de Sasave (cara norte). C: Sedimentos fluviales. D: Margas meteorizadas. Ac: porcentajes acumulados. Las partículas de carbonato no ban sido eliminadas en el análisis granulométrico. 
El Monasterio desapareció de los registros documentales a finales del siglo XVIII. Una gran colada de piedras depositó enormes volumenes de sedimentos mal clasificados, quedando la iglesia casi completamente enterrada hasta mediados del siglo XX.

El tamaño de la lengua de derrubios es de alrededor de 1 kilómetro de largo y 200-300 m de ancho, ocupando completamente el fondo de valle. El espesor es desconocido, aunque es de al menos $10 \mathrm{~m}$ en la excavación alrededor de la iglesia. En superficie, especialmente en el tramo medio, se reconocen coladas de piedras individuales, compuestas por bloques alargados y aplanados (correspondientes a la forma original de los bloques de areniscas procedentes del flysch). Alrededor de la iglesia la estructura del depósito muestra una mezcla de matrizfina ( 30 por ciento del total) gravas y bloques, sin ninguna organización (no se observa orientación preferente de las gravas ni estructuras fluviales), típica de un movimiento en masa en el que el agua facilita el movimiento pero no es un agente de transporte. El excelente estado de conservación de la iglesia sugiere que el movimiento de la colada no fue muy violento.

La Fig. 4 muestra los contrastes en la composición granulométrica entre la matriz fina de la colada de piedras, los depósitos fluviales del barranco de Calcín y las margas meteorizadas presentes en la cuenca. La matriz de la colada de piedras es claramente más arcillosa que la propiamente fluvial, confirmando que en la colada de piedras el papel del agua fue limitado, como corresponde a un movimiento en masa.

La cuenca en la que se desarrolló la colada de piedras tiene una superficie de $3.2 \mathrm{Km}^{2}$ y su altitud va de 970 a $1822 \mathrm{~m}$ s.n.m. En la actualidad se halla completamente cubierta por un bosque denso de Pinus sylvestris. Sólo un pequeño sector de la cuenca aparece desnudo: un escarpe de falla que no parece haber aportado muchos sedimentos al fondo de valle. El resto de la cuenca es muy estable, sin coladas de piedras en las laderas ni cabeceras activas ni rills, de manera que es imposible imaginar una gran producción de sedimentos en el estado actual de la cuenca.

Sin embargo, en siglos anteriores las cosas debieron ser muy diferentes, cuando los campos de cultivo ocuparon la mayor parte de las laderas por debajo de $1600 \mathrm{~m}$ s.n.m. El arado romano fue introducido en esta región inmediatamente después de la construcción del Monasterio y ello facilitó el cultivo en difíciles condiciones topográficas. Los bordes de los antiguos campos, ahora abandonados, pueden verse en toda la cuenca. En estas condiciones rills, pequeñas coladas de piedras y otros movimientos en masa (deslizamientos planares, slumps) pueden aportar mucho sedimento durante décadas acumulándose en almacenes temporales hasta que, durante lluvias muy intensas, se desencadena una gran colada de piedras (ver también CAINE, 1980; DAVIES et al., 1992). 
Figura 5.

Esquema geomorfológico de los movimientos en masa en la cara meridional del flysch $y$ detalle de las coladas de piedras de Espuéndolas. 1: Divisorias principales. 2: Cabalgamiento. 3: Fallas. 4: Deslizamientos rotacionales. 5: Cicatrices de movimientos en masa. 6: Coladas de piedra y barro. 7: Rellanos antiguos. 8: Acumulación de cabecera. 9: Colada de piedras reciente. 10: Coladas de piedras antigua (Martí Bono et al., en prensa).
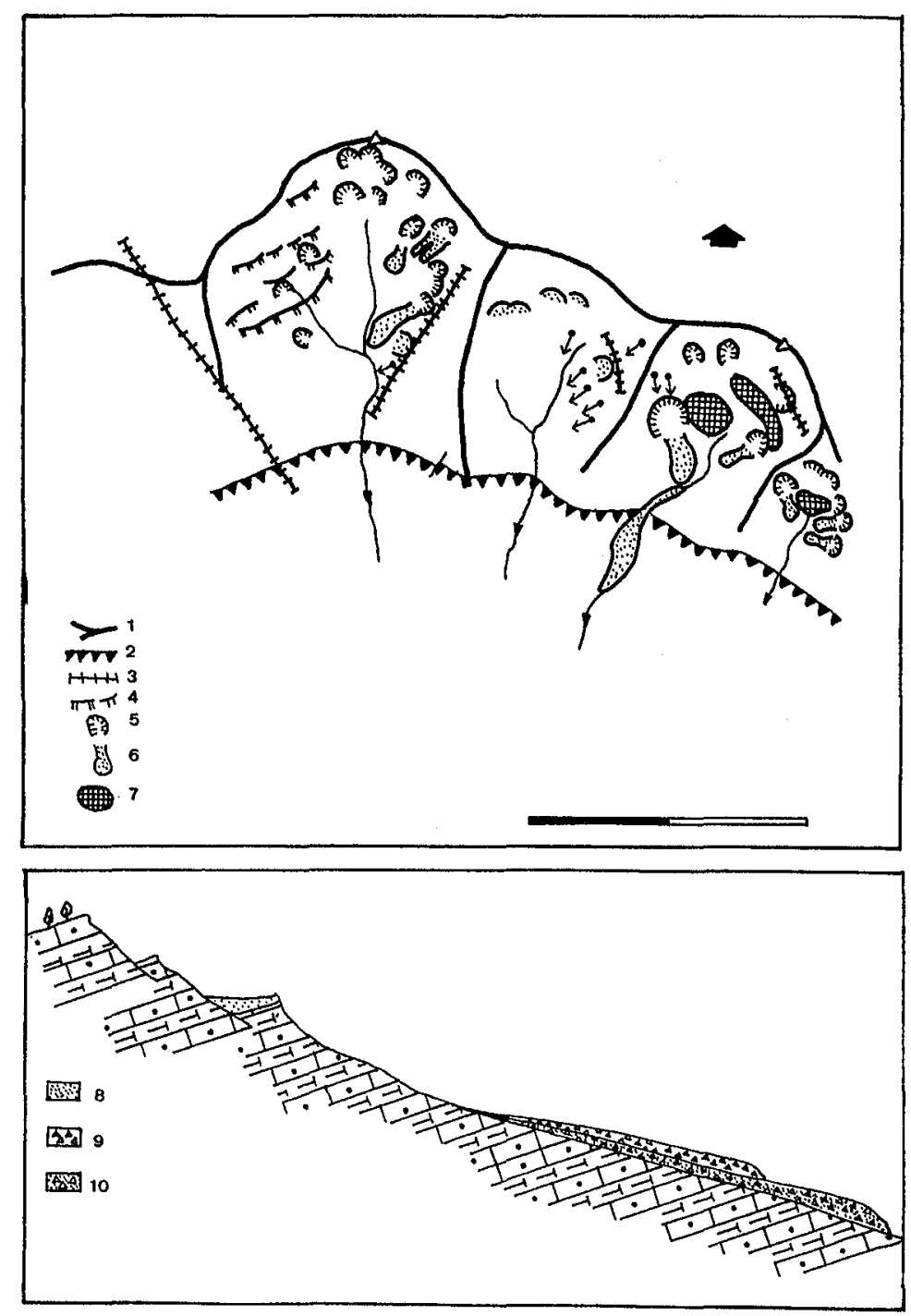

Las dos grandes coladas de piedras detectadas en San Adrián de Sasave están separadas unos 600 años. Esto significa, por un lado, que el desarrollo de grandes coladas de piedras necesita en esta región largos periodos de acumulación de sedimentos. $\mathrm{Y}$, por otro, que la precipitación capaz de desencadenar un fenómeno de este tipo tiene, como cabría esperar, un periodo de recurrencia muy largo.

El segundo ejemplo corresponde a la colada de piedras de Espuéndolas, que se localiza en el sector más meridional del flysch, en contacto con las margas eocenas de la Depresión Interior (Val Ancha). Las laderas muestran una gran actividad geomorfológica; con slumps y coladas de piedras, en gran parte ligada a la presencia de varias fallas (Fig. 5). El relieve se caracteriza por la presencia de amplias cabeceras pertenecientes a ciclos de erosión muy antiguos, probable- 
mente de comienzos del Cuaternario, cuando se inició la organización del relieve en la Depresión Interior.

El fondo de estas cabeceras está rellenado por un depósito potente de origen desconocido, compuesto principalmente por clastos angulosos empastados en una matriz arcillosa-margosa. No debe rechazarse la posibilidad de que este depósito sea muy reciente, como consecuencia de la deforestación. De hecho, las laderas meridionales del flysch han sido cultivadas y pastoreadas durante siglos (PUIGDEFÁBREGAS \& FILLAT, 1986). La otra posibilidad -un depósito acumulado durante la primera mitad del Holoceno- no es aceptable, pues este sector estuvo cubierto por bosques densos y en este caso la producción de sedimento hubiera sido muy limitada. La atribución del depósito a periodos fríos del Pleistoceno debe rechazarse también, ya que las características de los clastos no son similares a las de depósitos de climas muy fríos.

La consecuencia más importante de la acumulación de sedimento en cabeceras antiguas es la formación de grandes movimientos en masa en forma de coladas de piedras. El factor causante es la erosión remontante del barranco actual, que desestabiliza las laderas y el depósito pobremente consolidado de la cabecera (GARCÍA RUIZ \& PUIGDEFÁBREGAS).

En el caso de Espuéndolas (con una superfice de cuenca de $1.2 \mathrm{~km}^{2}$ y una altitud entre 970 y $1466 \mathrm{~m}$ s.n.m.) se han identificado dos grandes coladas de piedras, detectadas principalmente por el estado de la colonización vegetal. La más antigua es también la más voluminosa, ocupando todo el fondo de valle en una distancia de $600 \mathrm{~m}$, con una anchura de $150 \mathrm{~m}$ cerca del final de la lengua. La cubierta vegetal está dominada por la presencia de Buxus sempervirens, un matorral que necesita décadas para colonizar el suelo. Esta colada antigua está incidida por un barranco activo y por varios canales inactivos, probablemente formados en los momentos finales del evento. La estructura interna muestra un depósito caótico con bloques y gravas envueltos en una matriz limo-arcillosa, con intercalaciones de sedimentos más fluviales e incluso paleocanales rellenados por gravas angulosas. Su edad no ha podido ser determinada, pero pertenece a tiempos históricos recientes por su aspecto muy fresco.

Sobre parte de esta colada de piedras se ha desarrollado una segunda colada más corta y algo más estrecha, con un espesor no superior a 3 metros. Está colonizada por plantas herbáceas y matorrales submediterráneos que invaden fácilmente nuevos ambientes (por ej., Genista scorpius). El depósito está compuesto por bloques flotantes en una matriz margosa dominante. En la parte derecha entierra parcialmente una cabaña ganadera que sobrevivió al empuje del movimiento en masa. Este evento es muy reciente, ya que la fotografía aérea de 1957 sólo muestra la primera colada de piedras, mientras la segunda aparece en la fotografia aérea de 1978. 
Es evidente que los ejemplos de grandes coladas de piedras citados aquí están además estrechamente relacionados con precipitaciones de gran intensidad en un contexto topográfico y litológico determinado, pero el papel de la degradación paisajística parece muy claro: su funcionamiento ha tenido lugar en cuencas intensamente perturbadas, desprovistas del bosque original y cultivadas de forma general a pesar de las fuertes pendientes. En otros casos, no obstante, está más clara la influencia casi exclusiva del evento pluviométrico de baja frecuencia. Así, la catástrofe de Biescas ( 7 de agosto de 1996) en la cabecera del río Gállego alteró profundamente el curso bajo del barranco de Arás y desplazó decenas de miles de toneladas de sedimentos en unos pocos minutos (GARCÍA RUIZ et al., 1996a; WHITE et al., en prensa). Fenómenos similares han tenido lugar en otros puntos del Pirineo Central en las últimas décadas: así durante las lluvias torrenciales del 6 al 8 de noviembre de 1982 (BRU et al. 1984) el cono de deyección de la Guingueta (Valle del Noguera Pallaresa) fue invadido por sucesivas coladas de piedras, y el cono de deyección del barranco Remáscaro (Valle del Esera) fue removilizado con un pico de crecida de $108 \mathrm{~m}^{3} \cdot \mathrm{s}^{-1}$ (MARTÍ $\&$ PUIGDEFÁBREGAS, 1983). DAUMAS (1964) reseñó inundaciones catastróficas ligadas a fuertes tormentas estivales' (2-3 de agosto de 1963) en los valles del Esera, Isábena, Noguera Ribagorzana y Arán, con acumulaciones de más de 2 m de sedimentos en los fondos de valle, destrucción de una aldea y reactivación de antiguos conos de deyección.

\subsection{La erosión ligada a la agricultura de laderas}

Durante siglos las laderas localizadas entre 700 y $1500 \mathrm{~m}$ han sido quemadas, pastoreadas y cultivadas. La actividad agricola es conocida en el Pirineo desde 6400 B.P. (BALDELLOU \& UTRILLA, 1994; RODANÉS \& RAMÓN, en prensa). El análisis polínico de los sedimentos ha suministrado información sobre actividades humanas y su repercusión sobre la evolución del medio natural desde el Neolítico, aunque son necesarias más dataciones absolutas y una mayor resolución temporal para identificar con precisión los cambios habidos durante el Neolítico, la Romanización o la Edad Media (LÓPEZ, 1994). En el Pirineo Central la influencia humana empieza a ser importante en la vertiente septentrional entre 5000 y $4000 \mathrm{BP}$, favoreciendo el haya frente al abeto, y, a partir del 2000 $\mathrm{BP}$, se generaliza a todos los valles, aumentando la presencia de indicadores antrópicos y signos de deforestación (MONTSERRAT, 1992). A partir de estudios antracológicos llevados a cabo en el sur de Francia y Pirineos orientales, LÓPEZ et al. (1997) señalan que el inicio de la antropización se produce entre $6000 \mathrm{y}$ 4000 B.P., con la extensión de Buxus en los pisos mesomediterráneo superior y supramediterráneo. A partir del 4000 BP la antropización es general y la vegetación se caracteriza por la instalación de las garrigas y de matorrales diversos. 
Existen evidencias de erosión acelerada en la Edad del Hierro (2650-2500 B.P.), cuando bajo condiciones climáticas parecidas a las actuales se inician procesos de incisión en las laderas (GONZÁLEZ et al., 1994-96). Desde entonces se ha constatado la destrucción de las laderas regularizadas que se habían formado en la Edad del Bonce (3800-3100 B.P.). De acuerdo con el modelo evolutivo de GONZÁlEZ et al. (1994-96), confirmado con los estudios de SANCHO et al. (1988), PEÑA \& GONZÁLEZ (1992) y PEÑA \& RODANÉS (1992), la erosión de las laderas en áreas próximas al Pirineo alcanzó valores muy importantes en época romana (200 B.C.-500 A.D.) y, especialmente durante la Edad Media (5001500 A.D.) y Edad Moderna (1500-1850 A.D.). SANCHO et al. (1991) han estimado tasas de erosión-acumulación de sedimentos entre 14 y 15 tm/Ha/año durante la época romana).

Otros estudios llevados a cabo en montañas españolas confirman el descenso del porcentaje de polen de pino y la aparición de gramíneas cultivadas en torno a 3000 BP (por ejemplo, en el Sistema Ibérico burgalés: PEÑALBA, 1989). En la Sierra de la Estrella (Sistema Central, Portugal) los diagramas polínicos elaborados para varias turberas y lagos situados entre 1400 y $1900 \mathrm{~m}$ s.n.m. muestran un claro período de máxima degradación del bosque de robles entre 2500 y $1600 \mathrm{BP}$, coincidiendo con la introducción de Castanea. En torno a 1400 BP se observa una recuperación del bosque, así como una gran degradación de la vegetación, erosión del suelo y cultivo de cereales durante la Edad Media (VAN DER BRINK \& JANSSEN, 1985; JANSSEN, 1994). En el Pirineo Oriental (depósitos de Bañolas y Pla de l'Estany en Gerona) se ha observado que en los últimos 1700 años la cubierta arbórea se reduce a la vez que aumenta el porcentaje de taxones cultivados (Olea y Cerealia) y de matorrales ruderales (Ericaceae, Plantago, Chenopodiaceae) (BURJACHS, 1994; PÉREZ-OBIOL \& JULIÀ, 1994). En el Sistema Ibérico, el depósito de La Cruz (Cuenca) ha permitido el estudio de la historia de la vegetación y el uso del suelo en los últimos 1000 años, confirmando la expansión de la agricultura en época árabe, así como la importancia de los incendios durante la conquista cristiana y la expansión de la Mesta, traduciéndose en un notable descenso de los taxones arbóreos (BURJACHS, 1996; BURJACHS et al., 1997).

Aunque las etapas de ocupación agrícola del territorio permanecen confusas, algunos autores (BIELZA et al., 1986) señalan que los momentos culminantes de la presión agrícola en el Pirineo se producen a principios del siglo XIV, durante el XVI y en el siglo XIX. Es importante tener en cuenta que durante el siglo XIX se alcanza el máximo demográfico, coincidiendo con el inicio de la crisis de la ganadería, lo que explicaría el cultivo de áreas muy marginales. Por otra parte, diversos autores aluden a una ampliación del espacio agrícola durante la Edad Media (ver, por ej., BUESA, 1978), en parte debido a la fuerte presión social, con una gran masa de cultivadores muy cerca de la condición servil (SESMA, 1980). 


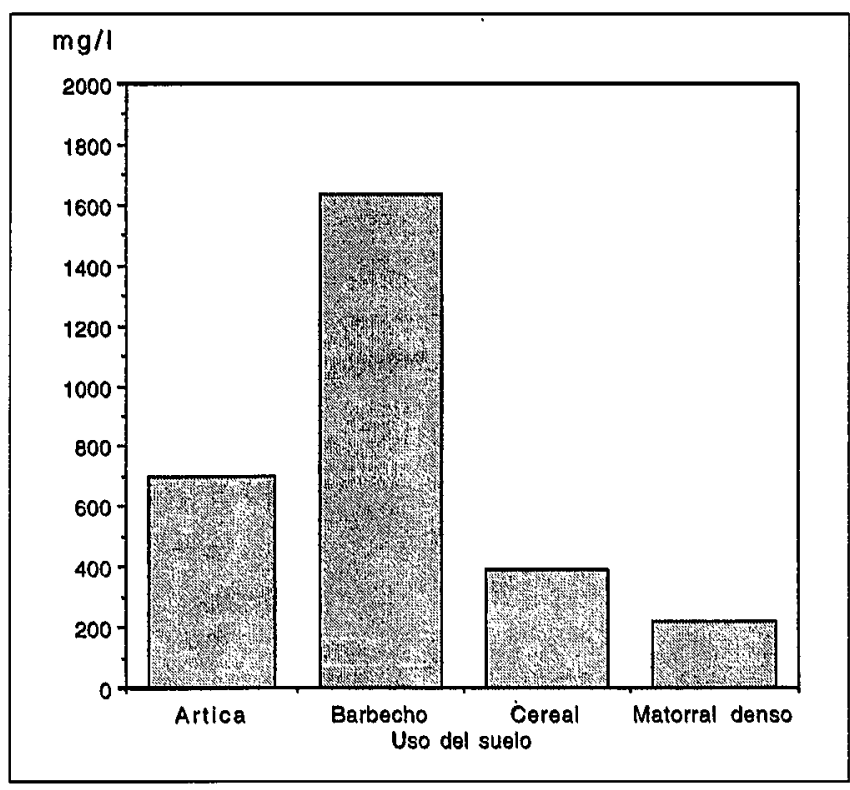

Figura 6.

Concentración de sedimentos en varios usos del suelo, con información procedente de la Estación Experimental "Valle de Aisa" (García Ruiz et al., 1996).

Para comprender la importancia de la agricultura en la evolución del paisaje pirenaico basta considerar que la superficie agrícola ha ocupado por término medio el $28.1 \%$ del territorio situado por debajo de $1600 \mathrm{~m}$. Sólo el $22.5 \%$ de esos campos pueden catalogarse como llanos, sin problemas de erosión, y un $36.4 \%$ como bancales. El resto se localiza en laderas muy pendientes a veces con sistemas de drenaje y pequeños muros en la parte baja (LASANTA, 1989). Los peores campos, llamados localmente articas, ocupaban laderas convexas o rectas, sin ningún tipo de medidas de conservación del suelo. Se cultivaban tras la roturación y quema del matorral, y las cenizas se empleaban para abonar un suelo muy pobre en nutrientes (RUIZ-FLAÑO, 1993). Al cabo de 2 ó 3 años de cultivo cerealista se abandonaban, para volver a cultivarse 25 o 30 años después, según un sistema típico de agricultura itinerante.

La sustitución del bosque y del matorral denso por campos de cultivo tuvo importantes repercusiones geomorfológicas e hidrológicas. Los estudios realizados en la Estación Experimental Valle de Aísa confirman que la agricultura cerealista en laderas eleva los coeficientes de escorrentía, la concentración de sedimentos y, en última instancia, la pérdida de suelo. La Fig. 6, muestra que la artica y el barbecho producen la mayor concentración de sedimento frente al comportamiento muy moderado del matorral denso (GARCÍA RUIZ et al., 1995 y 1996b). El mantenimiento de este sistema durante siglos, e incluso su ocasional intensificación, es responsable del estado actual de muchos suelos en laderas de montaña: escasa potencia de los horizontes más fértiles, abundante pedregosidad superficial, que puede llegar a ser del $100 \%$, incisiones poco marcadas pero eficaces en el transporte de materiales finos (RUIZ FLAÑO \& 
GARCÍA RUIZ, 1990), pequeñas coladas de piedras y cabeceras activas de torrentes. En esas condiciones la colonización vegetal avanza muy lentamente y no puede borrar en unas pocas décadas la presión humana durante siglos. Es importante tener en cuenta que la agricultura nómada llegó a representar más del 75\% del espacio cultivado en algunos valles (LASANTA, 1989).

Conviene no olvidar que, durante siglos, muchos campos en laderas pendientes han sido cultivados también con viñas, en lugares claramente inadecuados topográfica y climáticamente (BUESA, 1978). Este hecho no haría sino favorecer los procesos de arroyamiento superficial y el aumento de la pedregosidad del suelo, como han demostrado experimentalmente diversos estudios, incluso en pendientes moderadas (LASANTA \& SOBRÓN, 1988; RICHTER, 1989).

Estudios llevados a cabo en la cuenca experimental Loma de Arnás (GONZÁLEZ et al., 1997) confirman que durante el sistema tradicional casi toda la cuenca era activa desde el punto de vista de la producción de sedimentos. En la actualidad, 30 años después de que se haya abandonado la actividad agrícola, la zona activa representa alrededor del $1 \%$ de la superficie de la cuenca.

Al estudiar la evolución del tamaño de los sedimentos a lo largo del río Aurín (Fig. 7), se comprueba un incremento a partir del kilómetro 12, coincidiendo con la llegada de afluentes procedentes de los sectores tradicionalmente cultivados. Este anómalo cambio de tamaño, que no puede atribuirse a un cambio litológico o de pendiente en las cuencas de los afluentes, tiene que deberse a un aumento en la capacidad de transporte de sedimentos al drenar cuencas deforestadas con avenidas más intensas (GARCÍA RUIZ et al., 1997). De igual forma, GÓMEZ VILLAR (1996) comprobó que algunas características -especialmente el tamaño- de los conos de deyección en el valle del Gállego y en el Sistema Ibérico estaban estrechamente relacionadas con la superficie ocupada por antiguos campos de cultivo.

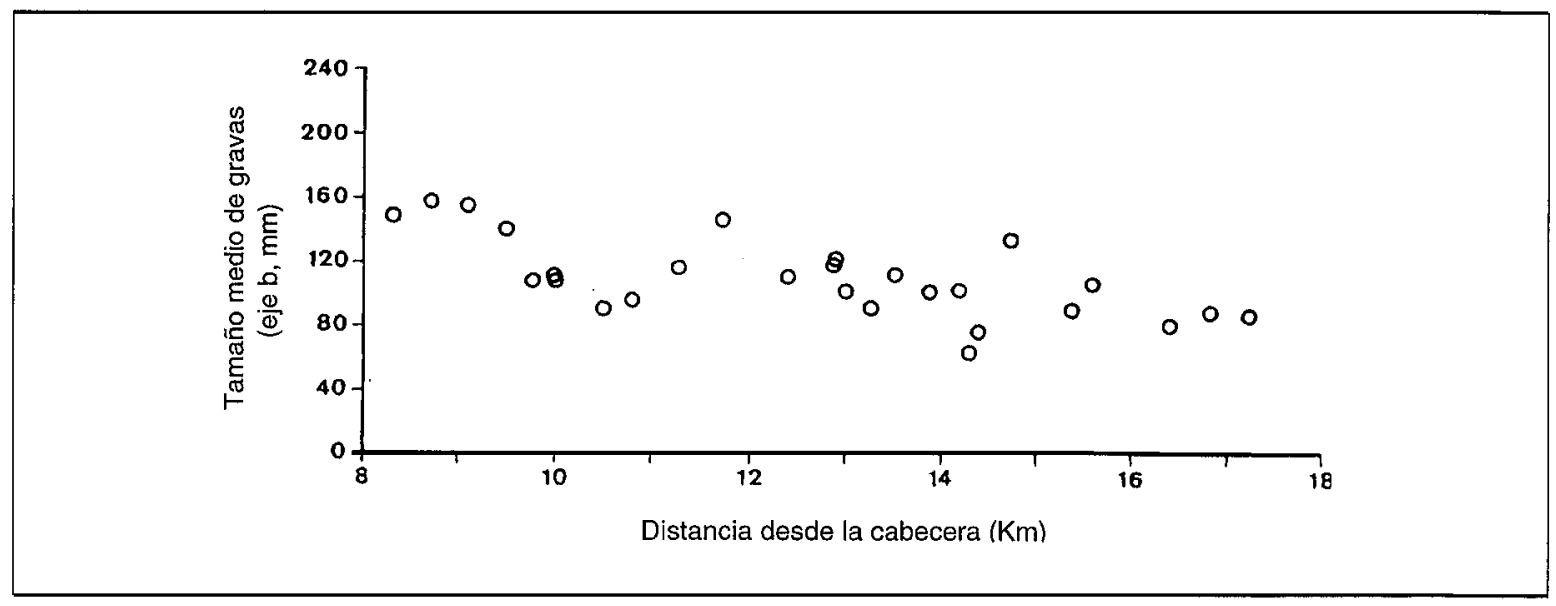

Figura 7. Evolución del tamaño de las gravas a lo largo del curso del río Aurín. 
A otra escala, el crecimiento del delta del Ebro desde época romana puede atribuirse a la deforestación y a la agricultura de laderas en el conjunto de la cuenca, aunque no existen evidencias que relacionen directamente uno y otro fenómeno. Los estudios de MALDONADO (1983) y del MOPU (cifr. Mariño, 1990) confirman que la línea de costa llegaba a Amposta, entonces puerto de mar, unos $12 \mathrm{Km}$ tierra adentro en la actualidad. Entre los siglos XV y XIX el delta experimentó una fuerte expansión espacial que no puede atribuirse simplemente a la fluctuación climática de la Pequeña Edad del Hielo y sus repercusiones geomorfológicas. Es en ese momento cuando tiene lugar de manera general la ocupación de las laderas para el cultivo de cereales.

\section{Discusión y conclusiones}

Históricamente la actividad humana en el Pirineo Central español se ha caracterizado por la ampliación de las áreas de pastos subalpinos a costa del piso superior del bosque y por el cultivo de los fondos de valle, rellanos colgados y laderas solanas muy pendientes en la montaña media. El paisaje actual conserva las huellas de una actividad agrícola y ganadera que ha reducido la superficie de bosque y ha cultivado todo lo posible, incluso en condiciones muy marginales.

La transformación del paisaje ha sido continua a lo largo de los últimos 4 milenios, pero algunos hitos son especialmente importantes. Así, la ampliación de los pastos subalpinos está muy localizada en torno a los siglos XI y XII, coincidiendo con la expansión de los sistemas trashumantes y de los pequeños reinos cristianos hacia la Depresión del Ebro. El espacio agrícola ha debido sufrir ampliaciones progresivas antes del siglo XIV y probablemente ya habría alcanzado su máxima superficie en el siglo XVI, como sugieren BIELZA et al. (1986), manteniendose con pequeñas fluctuaciones hasta el máximo demográfico del siglo XIX. Lamentablemente no hay registros lacustres en la montaña media pirenaica que hayan permitido seguir cuidadosamente la evolución de la vegetación y de los ritmos de sedimentación, como sí fue posible en cambio con la alta montaña (MONTSERRAT, 1992).

Las consecuencias hidrológicas y geomorfológicas de los impactos de origen humano son fáciles de deducir pero a veces son difíciles de relacionar con los hechos reales, sobre todo cuando se remontan mucho en el tiempo. La consecuencia más evidente -comprobada mediante cartografía geomorfológica (GARCÍA RUIZ \& PUIGDEFÁBREGAS, 1982) y SIG (GONZÁLEZ et al., 1995) es la ampliación superficial de las áreas fuentes de sedimentos. Las cuencas mas alteradas llegaron a ser en su totalidad activas desde un punto de vista geomorfológico e hidrológico, favoreciendo la producción y entrega de sedimentos (sediment yield and delivery) y la intensificación de los picos de crecida. El cre- 
cimiento de algunos conos de deyección (GÓMEZ VILLAR, 1996) y el predominio de la carga gruesa en llanuras aluviales con cauces muy inestables parecen estar relacionados con un prolongado periodo en el que los aportes de sedimentos desde las laderas provocaron un desequilibrio con la capacidad de evacuación de los cauces. Sólo en las últimas décadas, cuando las áreas fuentes de sedimentos se han contraido espacialmente (GONZÁLEZ et al., 1997), los cauces han entrado en una fase de incisión y de estabilización.

Donde mejor se han podido comprobar los efectos de la bumanización del paisaje es en alta montaña. La deforestación medieval causó un espectacular incremento de la erosión y de la energía de transporte. En lagos de alta montaña se pasó de un ritmo muy lento de sedimentación, con predominio de partículas orgánicas procedentes de un medio forestal muy autorregulado, a tasas muy elevadas de sedimentación de aportes detríticos, a la vez que en los espectros polínicos se comprueba la sustitución de especies forestales por comunidades herbáceas. Todavía hoy muchos de los suelos deforestados se ven afectados por movimientos en masa de pequeña envergadura (deslizamientos planares, solifluxión, terracillas). Muchas laderas han perdido la mayor parte del suelo.

Las grandes coladas de piedras parecen también ligadas a la deforestación, los incendios y el cultivo cerealista. Pero el factor desencadenante no es sólo la gran producción de sedimentos en el conjunto de la cuenca, sino un evento pluviométrico de gran intensidad. Estas lluvias, en verano y en otoño, son muy locales, pero pueden alcanzar valores superiores a $150 \mathrm{~mm}$ en una o dos horas o incluso a $600 \mathrm{~mm}$ en 24 horas (GARCÍA RUIZ et al., 1996a). En esas condiciones pueden generarse arrastres de grandes volúmenes de sedimentos heterométricos en forma de coladas de piedras, rellenando fondos de valle enteros y afectando a tierras de cultivo y edificios. En los dos casos estudiados (San Adrián de Sasave y Espuéndolas) el fenómeno se ha repetido en varias ocasiones confirmando la recurrencia de eventos extremos.

\section{Agradecimientos}

Este trabajo se ha elaborado con la yuda de los siguientes proyectos de investigación: "Producción de sedimentos y escorrentía como consecuencia de los cambios de uso del suelo en áreas de montaña" (AMB96-0401) y "Procesos hidrológicos en cabeceras mediterráneas frágiles o degradadas" (AMB95-0986-CO2), financiados por la CICYT. 
JOSÉ M. ${ }^{a}$ GARCÍA RUIZ - BLAS L. VALERO GARCÉS

\section{Referencias bibliográficas}

ANDRÉS, T. (1992): Relaciones Aragón-Litoral Mediterráneo. Sepulcros del Neolítico al Bronce. Congreso Aragón-Litoral Mediterráneo. Intercambios culturales durante la Prebistoria. Institución Fernando El Católico, pp. 469490, Zaragoza.

BALDELlOU, V. \& UTRILLA, P. (1994): Le Néolithique en Aragón. Les civilisations méditérranéennes. XXIX Congrès Prébistorique de France, Carcassonne.

BALLANTYNE, C.K. (1994): Holocene mass movement on Scottish mountains: dating, distribution and implications for environmental change. In. Solifluction and climatic variations in the Holocene (B. Frenzel, ed.), Special issue ESF, pp. 71-86, Gustav Fisher Verlag.

BIELZA, V., CORRAL, J.L., ESCOLANO, S., LALIENA, C., SESMA, A. \& UBIETO, A. (1986): Estudio bistórico-geográfico del valle de Bielsa (Huesca). Instituto de Estudios Altoaragoneses, 224 pp., Huesca.

BRU, J., SERRAT, D. \& VILAPLANA, J.M. (1984): La dinámica geomorfológica de la cuenca del torrente de Jou-La Guingueta (Noguera Pallaresa). Inestabilidad de laderas en el Pirineo, ETSI Caminos, Canales y Puertos, Barcelona pp. 121-130.

BRUNSDEN, D. (1979): Mass movements. In Process in Geomorphology (C.E. Embleton and J.B. Thornes, eds), Arnold, London, pp. 130-186.

BUESA, D. (1978): El rey Sancho Ramírez. Guara Editorial, 126 pp., Zaragoza.

BURJACHS, F. (1994): The palinology of the Upper Pleistocene and Holocene of the North-East Iberian Peninsula: Pla de l'Estany (Catalonia). Historical Biology, 9: 17-33.

BURJACHS, F. (1996): La secuencia palinológica de La Cruz (Cuenca, España). In Estudios palinológicos (B. Ruiz Zapata et al., eds.). Publicaciones de la Universidad de Alcalá, pp., 31-36, Alcalá de Henares.

BURJACHS, F., GIRALT, S., ROCA, J.R., SERET, G. \& JULIÁ, R. (1997): Palinología holocénica y desertificación en el Mediterráneo Occidental. In El paisaje mediterráneo a través del espacio y del tiempo. Implicaciones en la desertificación (J.J. Ibáñez, B.L. Valero y C. Machado, eds.), Geoforma Ediciones, pp. 379-394, Logroño.

CAINE, N. (1980): The rainfall intensity-duration control of shallow landslides and debris flows. Geografiska Annaler, 62A: 23-27.

DAUMAS, M. (1964): Les crues du 3 août dans les hautes vallées aragonaises et catalanes. Rev. Géogr. Pyr. S.O., 35: 305-310. 
DAVIES, T.R., PHILLIPS, T.J. \& PEARCE, A.J. (1992): Debris flow behaviour-An integrated overview. LAHS Publ., 209: 217-225.

DE JONG, C. (1992): A catastrophic flood/multiple debris flow in a confined mountain stream: an example from the Schmiedlaine, southern Germany. IAHS Publ., 209: 237-246.

GAMPER, M. (1994): Holocene solifluction in the Swiss Alps: Dating and climatic implications. In Solifluction and climatic variations in the Holocene (B. Frenzel, ed.), Special issue ESF, pp. 1-10, Gustav Fisher Verlag.

GARCÍA RUIZ, J.M. \& PUIGDEFÁBREGAS, J. (1982): Formas de erosión en el flysch eoceno surpirenaico. Cuadernos de Investigación Geográfica, 8: 85-128.

GARCÍA RUIZ, J.M. \& PUIGDEFÁBREGAS, J. (1984): Inestabilidad de laderas en el Pirineo aragonés: Tipos de movimientos y su distribución geográfica. In Inestabilidad de laderas en el Pirineo, ETSI de Caminos, pp. 141-152, Barcelona.

GARCÍA RUIZ, J.M., PUIGDEFÁBREGAS, J. \& CREUS, J. (1986): La acumulación de nieve en el Pirineo Central y su influencia hidrológica. Pirineos, 127: 27-72.

GARCÍA RUIZ, J.M., ALVERA, B., DEL BARRIO, G. \& PUIGDEFÁBREGAS, J. (1990): Geomorphic processes above timberline in the Spanish Pyrenees. Mountain Research and Development, 10(3): 201-214.

GARCÍA RUIZ, J.M., LASANTA, T., ORTIGOSA, L., RUIZ FLAÑO, P., MARTÍ, C. \& GONZÁLEZ, C. (1995): Sediment yield under different land uses in the Spanish Pyrenees. Mountain Research and Development, 15(3): 229-240.

GARCÍA RUIZ, J.M., WHITE, S.M., MARTí, C., VALERO, B., ERREA, M.P. \& GÓMEZ VILLAR, A. (1996a): La catástrofe del barranco de Arás (Biescas, Pirineo aragonés) y su contexto espacio-temporal. Instituto Pirenaico de Ecología, Zaragoza, 54 pp.

GARCÍA RUIZ, J.M., LASANTA, T., GONZÁlEZ, C., MARTÍ, C., WHITE, S., ERREA, M.P. \& MAESTRO, M. (1996b): La agricultura marginal como fuente de sedimentos en el Pirineo Central. IV Reunión de Geomorfología, O Castro, pp. 123-132.

GARCÍA RUIZ, J.M., LASANTA, T., GONZÁLEZ, C., MARTÍ, C., WHITE, S. \& ORTIGOSA, L. (1997): Sediment sources during the traditional land-use system in the Spanish Pyrenees. Physics and Chemistry of the Earth, 22 (3-4): 351-354.

GÓMEZ VILLAR, A. (1996): Conos aluviales en pequeñas cuencas torrenciales de montaña. Geoforma Ediciones, Logroño, 191 pp. 
JOSÉ M. ${ }^{a}$ GARCÍA RUIZ - BLAS L. VALERO GARCÉS

GONZÁlEZ, C., GARCÍA RUIZ, J.M., MARTÍ C., WHITE, S., ERREA, M.P. \& ARNÁEZ, J. (1997): Sediment sources in a small, abandoned farmland catchment, Central Spanish Pyrenees. Pbysics and chemistry of the Earth, 22 (3-4): 291-293.

GONZÁlEZ, C., ORTIGOSA, L., MARTÍ, C. \& GARCÍA RUIZ, J.M. (1995): The study of spatial organization of geomorphic processes in mountain areas using GIS. Mountain Research and Development, 15(3): 241-249.

GONZÁlEZ, J.R., RODRÍGUEZ, J.I. \& PEÑA, J.L. (1994-96): Aportació de la Geoarqueología al coneixement del poblament durant els Camps d'Urnes i l'Edat del Ferro a les valls inferiors dels rius Segre i Cinca. Gala, 3-5: 277-292.

HÖLLERMANN, P. (1985): The periglacial belt of mid-latitude mountains from a geoecological point of view. Erdkunde, 39: 259-270.

JANSSEN, C.R. (1994): Palynological indications for the extent of the impact of man during Roman times in the Western part of the Iberian peninsula. In Evaluation of land surfaces cleared form forest in the Mediterranean region during the time of the Roman Empire (B. Frenzel, ed.), Special issue ESF, pp. 15-22.

JOHNSON, A.M. \& RODINE, J.R. (1984): Debris flows. In Slope instability (d. Brunsden and D.B. Prior, eds.), John Wiley, Chichester, pp. 257-361.

LASANTA, T. (1988): The process of desertion of cultivated areas in the Central Spanish Pyrenees. Pirineos, 132: 15-36.

LASANTA, T. (1989): Evolución reciente de la agricultura de montaña: el Pirineo aragonés. Geoforma Ediciones, Logroño, 220 pp.

LASANTA, T. \& SOBRÓN, I. (1988): Influencia de las prácticas de laboreo en la evolución hidromorfológica de suelos cultivados con viñedo. Cuadernos de Investigación Geográfica, 14:81-98.

LEOPOLD, L.B. (1978): El Asunto del Arroyo. In Geomorpbology. Present problems and future prospects (C. Embleton, D. Brunsden and D.K.C. Jones, eds.), Oxford University Press, Oxford, pp. 25-39.

LÓPEZ, P. (1994): Forest, forest clearance and open land during the time of the Roman Empire in Spain. In Evaluation of land surfaces cleared from forest in the Mediterranean region during the time of the Roman Empire (B. Frenzel, ed.), Special issue ESF, pp., 23-36.

LÓPEZ, P., UZQUIANO, P. \& ARNANZ, A.M. (1997): La arqueobotánica como medio de aproximación al conocimiento del papel del hombre en el proceso de cambio de vegetación en la cuenca mediterránea. In El paisaje mediterráneo a través del espacio y del tiempo. Implicaciones en la desertifica- 
PROCESOS GEOMÓRFICOS HISTÓRICOS Y SU RELACIÓN CON LA ACTIVIDAD HUMANA

ción (J.J. Ibáñez, B.L. Valero y C. Machado, eds.), Geoforma Ediciones, pp. 363-377, Logroño.

MALDONADO, A. (1983): Dinámica sedimentaria y evolución litoral reciente del Delta del Ebro. In Sistema integrado del Ebro (M. Mariño, edr.), Madrid, pp. 33-60.

MARIÑO, M.G. (1990): Implications of climatic change on the Ebro Delta. In Climatic change and the Mediterranean (L. Veftic, J.D. Milliman and G. Sestini, eds.), E. Arnold, London, pp. 304-327.

MARSAN, G. \& UTRILLA, P. (1996): L'implantation du mégalithisme dans les passages des Pyrénées Centrales. Comparaison des vallées d'Ossau et TenaCanfranc. Pyrénées Prébistoriques. Arts et Sociétés, pp. 521-532, Paris.

MARTÍ, C. \& PUIGDEFÁBREGAS, J. (1983): Consecuencias geomorfológicas de las lluvias de noviembre de 1982 en las cabeceras de algunos valles pirenaicos. Estudios Geográficos, 170-171: 275-290.

MARTÍ, C., VALERO, B. \& GARCÍA RUIZ, J.M. (1997): Large, historical debris flows in the Central Spanish Pyrenees. Pbysics and Chemistry of the Earth.

MOLINILLO, M., LASANTA, T. \& GARCÍA RUIZ, J.M. (1997): Managing mountainous degraded landscapes after farmland abandonment in the Central Spanish Pyrenees. Environmental Management, 21: 1-13.

MONTSERRAT, J. (1992): Evolución glaciar y postglaciar del clima y la vegetación en la vertiente sur del Pirineo: Estudio palinológico. Instituto Pirenaico de Ecología, Zaragoza, 147 pp.

PEÑA, J.L. \& GONZÁLEZ, J.R. (1992): Modelo evolutivo de los cambios en la dinámica geomorfológica del Baix Cinca y Segre (Depresaión del Ebro) durante el Pleistoceno superior-Holoceno a partir de los datos geoarqueológicos. Cuaternario y Geomorfología, 6: 103-110.

PEÑA, J.L. \& RODANÉS, J.M. (1992): Evolución geomorfológica y ocupación humana en el cerro de Masada de Ratón (Baix Cinca, prov. de Huesca). Cuaternario y Geomorfología, 6: 81-90.

PEÑALBA, C. (1989): Dynamique de végétation tardiglaciaire et Holocène du Centre-Nord de l'Espagne d'après l'analyse pollinique. Ph. D. Thèse, $165 \mathrm{pp}$.

PÉREZ-OBIOL, R. \& JULIÁ, R. (1994): Stages of climatic change in a Mediterranean environment based on a 30,000 year pollen record. The lake Banyoles sequence. Quaternary Research, 41: 91-98.

PUIGDEFÁBREGAS, J. \& ALVERA, B. (1986): Aspectos biogeoquímicos de los ambientes de montaña. Jornades sobre bases ecologiques per la gestió ambiental, Barcelona, pp. 79-84. 
JOSÉ M. ${ }^{a}$ GARCÍA RUIZ - BLAS L. VALERO GARCÉS

PUIGDEFÁBREGAS, J. \& FILLAT, F. (1986): Ecological adaptation of traditional land uses in the Spanish Pyrenees. Mountain Research and Development, 6-10: 63-72.

PUIGDEFÁBREGAS, J. \& GARCÍA RUIZ, J.M. (1983): Parámetros físicos del suelo y dinámica de vertientes en el Pirineo Central. VIII Coloquio de Geógrafos Españoles, Barcelona, pp. 131-138.

RICHTER, G. (1989): Erosion control in vineyards of the Mosel-Region, FRG. Soil Technology Series, 1: 149-156.

RIJCKBORST, H. (1967): Hydrology of the upper-Garonne Basin (Valle de Arán, Spain). Leisde Geologische Medelingen, 40: 1-74.

RODANÉS, J.M. \& RAMÓN, N. (en prensa): El Neolítico antiguo en Aragón: Habitat y territorio. Zepbyrus.

RUIZ FLAÑO, P. (1993): Procesos de erosión en campos abandonados del Pirineo. Geoforma Ediciones, 190 pp., Logroño.

RUIZ FLAÑO, P. \& GARCÍA RUIZ, J.M. (1990): Some remarks on rill evolution on abandoned fields. Interation between agricultural systems and soil conservation in Mediterranean belt, pp. 18-25, Lisboa.

SANCHO, C., GUTIÉRREZ, M. \& PEÑA, J.L. (1991): Erosion and sedimentation during the upper Holocene in the Ebro Depression: Quantification and environmental significance. In Soil erosion studies in Spain (Sala, M., Rubio, J.L. and Garcia Ruiz, eds.), Geoforma Ediciones, pp. 219-228, Logroño.

SESMA, A. (1980): Aragón medieval. In Aragón en su Historia (A. Canellas, ed.), Caja de Ahorros de la Inmaculada, pp. 107-186, Zaragoza.

UBIETO, A. (1981): Historia de Aragón. La formación territorial. Oroel, Zaragoza.

VALERO, B. \& MARTÍ, C. (1997): Degradación ambiental e impacto antrópico: Técnicas y aportaciones desde la limnogeología. In Acción humana y desertificación en ambientes mediterráneos (J.M. García Ruiz and P. López, eds.), Instituto Pirenaico de Ecología, Zaragoza.

VAN DER BRINK, L. \& JANSSEN, C.R. (1985): The effect of human activities during cultural phases on the development of montane vegetation in the Sierra da Estrela, Portugal. Rev. Paleobot Palynol., 44: 193-215.

WHITE, S., GARCÍA RUIZ, J.M., MARTÍ, C., VALERO, B., ERREA, M.P. \& GÓMEZ VILLAR, A. (en prensa): The Biescas campsite disaster and its temporal and spatial context. Hydrological Processes. 